For submission to Geophys. Res. Lett.

\title{
Satellite Detection of Smoke Aerosols Over A Snow/Ice Surface By TOMS
}

\author{
N. C. Hsu', J. R. Herman², J. F. Gleason ${ }^{2}$, O. Torres ${ }^{3}$, C. J. Seftor ${ }^{1}$
}

\begin{abstract}
The use of TOMS (Total Ozone Mapping Spectrometer) satellite data demonstrates the recently developed technique of using satellite UV radiance measurements to detect absorbing tropospheric aerosols is effective over snow/ice surfaces. Instead of the traditional single wavelength (visible or infrared) method of measuring tropospheric aerosols, this method takes advantage of the wavelength dependent reduction in the backscattered radiance due to the presence of absorbing aerosols over snow/ice surfaces. An example of the resulting aerosol distribution derived from TOMS data is shown for an August 1998 event in which smoke generated by Canadian forest fires drifts over and across Greenland. As the smoke plume moved over Greenland, the TOMS observed $380 \mathrm{~nm}$ reflectivity over the snow/ice surface dropped drastically from $90-100 \%$ down to $30-40 \%$. To study the effects of this smoke plume in both the UV and visible regions of the spectrum, we compared a smoke-laden spectrum taken over Greenland by the high spectral resolution (300 to 800 $\mathrm{nm}$ ) GOME instrument with one that is aerosol-free. We also discuss the results of modeling the darkening effects of various types of absorbing aerosols over snow/ice surfaces using a radiative transfer code. Finally, we investigated the history of such events by looking at the nearly twenty year record of TOMS aerosol index measurements and found that there is a large interannual variability in the amount of smoke aerosols observed over Greenland. This information will be valuable for studies of radiation and transport processes in the Arctic
\end{abstract}

\footnotetext{
${ }^{1}$ Raytheon STX, Lanham, Maryland 20706

${ }^{2}$ NASA/ Goddard Space Flight Center, Code 916, Greenbelt, Maryland 20771

${ }^{3} \mathrm{UMBC} / \mathrm{JCET}$, Maryland
} 


\section{Introduction}

Detection of tropospheric aerosols over snow/ice surfaces is very important for the determination of the temperature and albedo of such surfaces from satellites [Key et al., 1993; Lindsay and Rothrock, 1993]. However, there are many obstacles using the traditional single wavelength method (e.g., AVHRR in either visible or infrared part of spectrum) to retrieve tropospheric aerosols. Using TOMS (Total Ozone Mapping Spectrometer) data, a new technique was developed using a pair of ultraviolet wavelengths to measure tropospheric aerosols over both land and water [Hsu et al., 1996; Herman et al., 1997; Seftor et al., 1997; Torres et al., 1998; Hsu et al., 1998]. Essentially, the presence of tropospheric aerosols can be detected by comparing the measured ratio of the backscattered radiances $I_{\lambda}$ at two wavelengths $(\lambda=340$ and $380 \mathrm{~nm}$ for Nimbus 7/TOMS; $\lambda=331$ and $360 \mathrm{~nm}$ for ADEOS/ and Earth-Probe/TOMS) to a calculated ratio based on a Rayleigh-scattering model atmosphere bounded by Lambertian surfaces. The logarithmic difference between measured and calculated ratios is defined as the aerosol index. Comparisons of the TOMS aerosol index with aerosol optical thickness measured by ground-based sun-photometer indicate a linear relationship between the two quantities [Hsu et al., 1998, Torres et al., 1998].

In this paper, we use satellite measurements from TOMS to demonstrate that the radiance ratio $\left(I_{\lambda 1} / I_{\lambda 2}\right)$, which represents the spectral contrast between the two UV wavelengths, can also be used to detect absorbing tropospheric aerosols over snow/ice surfaces. These results are consistent with theoretical calculations discussing the detection of aerosols and calculation of aerosol optical depths under a variety of conditions [Torres et al., 1998] . For highly reflective surfaces such as cloud and snow/ice, the effect of aerosol scattering becomes small compared to the reflection from 
the background surface, and it is difficult to detect aerosols which do not absorb UV or visible radiation (such as sulfates) over such a surface. Since the aerosol absorption interferes with the amount of Rayleigh scattering coming from below the aerosols, a change in spectral contrast due to the presence of aerosols still occurs. In this paper we use the UV technique with data from TOMS and GOME (Global Ozone Monitoring Experiment) to study smoke aerosols from Canadian forest fires that drift over Greenland.

\section{Observed Canadian smoke plume over Greenland}

Figure 1 shows 6 successive daily maps of smoke plumes from Canadian forest fires that occurred in August 1998, superimposed with NCEP $500 \mathrm{mb}$ winds and geopotential heights. On August 3, a major smoke plume was detected by TOMS in the Canadian Northwest Territories, following the prevailing wind and moving to the east. AVHRR images for the same day, which are available from the web site http://modarch.gsfc.nasa.gov/fire_atlas, also show hot spots in the region upstream of this plume west of Great Bear Lake. On August 4, an even more intense smoke plume was seen in the TOMS aerosol map extending for more than a thousand miles from the region near Great Bear Lake to Hudson Bay. Fires (hot spots) were also observed in the AVHRR images in the Northwest Territories near Great Bear Lake and Great Slave Lake as well as in the region near Manitoba west of Hudson Bay. The smoke plume on August 3 resided at the crest of a steep ridge at $500 \mathrm{mb}$. This ridge axis extended from the western United States to western Canada. Over the next several days, the smoke plume traveled with this ridge system without losing its identity and finally arrived at Greenland on August 6.

On August 7 and 8, the smoke plume from TOMS and the hot spots from AVHRR were 
observed again in Manitoba west of Hudson Bay, indicating the presence of new fires in this region. However, in the Atlantic the smoke plumes generated from the forest fires in the Northwest Territories a few days before still remained the dominant feature. It is interesting to note that in Figure 1, these plumes encountered a small disturbance embedded in the jet stream in the North Atlantic east of Newfoundland on August 7. As a result, a smoke filament was seen to wrap around the contour of the disturbance.

\section{Impact of absorption due to smoke aerosol on reflectance}

Since smoke contains black carbon, the smoke particles not only reflect solar radiation back to space, but also absorb radiation. To examine the net effect of tropospheric aerosols on solar radiation, we looked at the satellite-measured as well as the theoretically-predicted response of the reflectance to changes in aerosol loading. Figure 2 shows maps of the TOMS $380 \mathrm{~nm}$ reflectivity for August $5-8,1998$. The reflectivity is usually quite stable and uniform over Greenland, and thus can be used as a reference for satellite calibration purposes [Jaross et al., 1995]. On August 5, 1998, as shown in Figure 2, the reflectivity observed by TOMS was between 90 and 100\% over Greenland, consistent with the observation of no significant aerosol detected on this day. On August 6, the Canadian smoke plume moved over Greenland and the observed reflectivity dropped dramatically to a level of $30-40 \%$ over the area of intense smoke. During the next two days, August 7 and 8 , the smoke plume gradually thinned and stretched to the southeast. However, the darkening effect due to the presence of smoke was still very obvious over Greenland during these two days.

The high spectral resolution radiance measurements from the same time period by the Global Ozone Monitoring Experiment (GOME) instrument onboard the ESA ERS-2 satellite provide an 
excellent opportunity to study the wavelength dependence of the change in the reflectance due to smoke aerosols over Greenland. Figure 3 shows that for wavelengths longer than $325 \mathrm{~nm}$ the reduction in reflectance decreases with increasing wavelength. This is due to the enhanced role of multiple molecular scattering in the total-backscattered radiance as the radiation bounces several times between the aerosol layer and snow/ice surface before finally escaping into space. It indicates that the presence of the smoke aerosol does not reduce the reflectance uniformly at all wavelengths, but instead causes a strong spectral dependence, particularly in the UV part of the spectrum. This wavelength dependence results in the non-zero value of aerosol index discussed earlier. For wavelengths shorter than $325 \mathrm{~nm}$, the difference in reflectance between aerosol and aerosol-free conditions begins to diminish. This is most likely due to the ozone absorption in the stratosphere.

Figure 4 shows a radiative transfer calculation of how the change in $380 \mathrm{~nm}$ scene reflectivity responds to the presence of smoke over different underlying surfaces for three different aerosol models used in our study: non-absorbing ( $\mathrm{S} 1$; sulfate), weakly absorbing $\mathrm{C} 1$, and moderately absorbing aerosols C2. The solar zenith angle and altitude of the aerosols were assumed to be $40^{\circ}$ and $3 \mathrm{~km}$, respectively. The aerosol optical thickness at $380 \mathrm{~nm}$ was set to be 1 for all three aerosol types (see Torres et al. [1998] for details of the aerosol models). The results show that the Mie scattering from non-absorbing aerosols increases the scene reflectance over dark surfaces and has little impact on reflectance over highly reflective surfaces. On the other hand, absorbing aerosols can increase reflectance over dark surfaces, and decrease reflectance over bright surfaces. The magnitude of the change in reflectance and the critical reflectance where the effect changes sign are dependent on the properties of aerosols, particularly on their absorption characteristics. The theoretical calculations shown in Figure 4 suggest that the $380 \mathrm{~nm}$ reflectance of a highly reflective 
surface can be reduced by as much as $40 \%$ for moderately absorbing carbonaceous aerosols with a $380 \mathrm{~nm}$ optical thickness of 1 . This is comparable to the observed change in the reflectivity by TOMS and the observed difference in the GOME spectra.

Torres et al. [1998] used the same radiative transfer model to show that the ratio of TOMS $(340-380 \mathrm{~nm}$ ) aerosol index to aerosol optical thickness (at $380 \mathrm{~nm}$ ) is 1.8 for the $\mathrm{C} 1$ model and 2.9 for the $\mathrm{C} 2$ model for a solar zenith angle $40^{\circ}$, the nadir view, and assuming that surface reflectivity is Lambertian and equal to 0.6. Based upon the $\mathrm{C} 1$ and $\mathrm{C} 2$ models, we estimated that the maximum aerosol optical thickness observed over Greenland on August 6 and 7 was around $2-3$ at $380 \mathrm{~nm}$

\section{Interannual variability of biomass burning smoke observed over Greenland}

Figures $5 a$ and $5 b$ show the daily statistics indicating the size of the area covered by heavy smoke (TOMS aerosol index $>2$ ) observed by TOMS over Greenland and Canada, respectively. This nearly 20 year data series (with a gap in 1995) was constructed using TOMS level 3 gridded data from three satellites: Nimbus-7 (1979-1992), Meteor-3 (1993-1994), and Earth-Probe (1996present). Because of the precessing orbit of the Meteor- 3 satellite, only measurements made between 8 a.m. -4 p.m. local time were included in this time series. The TOMS aerosol measurements from Earth Probe were normalized to adjust for the difference in sensitivity to aerosols between Nimbus-7 and Earth-Probe TOMS in wavelengths used to detect aerosols [Hsu et al., 1998]. Since major boreal forest fires usually occur in the spring, summer, and early fall, we only include TOMS aerosol measurements from April to September in the time series to avoid very large solar zenith angle cases. The radiative transfer processes is more complicated when the air path is large, especially over snow/ice surfaces, and is beyond the scope of this study. 
It is apparent from Figure 5 that smoke was observed almost every year over the Canadian boreal forest, with a significant amount of interannual variability. Large areas of smoke were observed by TOMS in 1981, 1982, 1987, 1988, 1989, 1990, 1994, and 1998 over Canada, while smoke was seen over Greenland in 1981, 1987, 1988, 1989, 1990, 1994, and 1998. In the 1998 event, nearly one-third of Greenland was covered by smoke palls transported from Canada. By examining daily maps of the aerosol distribution seen by TOMS, we can track the movements of tropospheric aerosols back to the source regions. According to the TOMS data from 1979 to 1998 , we conclude that the absorbing aerosols (such as smoke) arriving at Greenland can be traced back to three major sources: Canadian forest fires, United States forest fires, and Chinese/ Russian forest fires. The peak seen in the smoke time series over Greenland during 1987 was due to smoke from the May 1987 Great China Fire, while the spike over Greenland in 1988 resulted from the long-range transport of the smoke from the Yellowstone fires in the United States. Alaskan fires also play a major role in contributing to the 1990 smoke level observed over Canada and Greenland.

Based upon the nearly 20 year record of TOMS aerosol measurements, the trajectories of smoke plumes transported over long distances from the boreal forest fires are often observed to be embedded in the polar and Arctic jet stream. We use the NCEP monthly averaged geopotential height at $500 \mathrm{mb}$ for August 1994 and August 1982, depicted in Figure 6 (top) and (bottom), respectively, to illustrate the role of the polar and Arctic jet stream in the long-range smoke transport. When the Arctic jet stream over Canada was very strong (e.g., in August 1994) the rapid flow associated with the jet stream provides a north pathway to transport the smoke plumes from Canada to Greenland. However, when the Arctic jet stream was weak and the polar jet stream was very strong (e.g., 1982), resulting in smoke plumes traveling across the Atlantic to Europe at lower 
latitudes south of Greenland.

\section{Concluding Remarks}

In this paper, we demonstrate the capability of the TOMS aerosol-index measurements to detect smoke aerosols over a snow/ice surface. A limited validation of the UV technique over snow/ice surfaces was conducted by comparing the TOMS aerosol index with the ground-based chemical measurements obtained in a Greenland ice core expedition in August 1994 [Dibb, et al, 1996; Currie, et al., 1998]. The amounts of smoke derived from the analyses of the chemical composition collected at the surface during the 10 day time period of the expedition over Greenland correlate well with the overpass TOMS aerosol index data from the same days.

Fire statistics (1980-1989) show that, next to the occurrence of Russian fires, Canadian fire activity is the largest in the boreal forest zone in term of the number of fires and area burned [Stocks, 1991]. We have found that during the recent 1998 Canadian forest fire event, nearly one-third of Greenland was covered by the smoke palls transported from Canada and the reflectance over the snow/ice surface in Greenland was reduced due to such aerosols by as much as $60 \%$. Because of the large changes, the effect of such smoke events could be important in determining the radiative energy budget, particularly in the polar region. Since the large smoke plumes were often observed to be embedded in the polar and Arctic jet stream, further studies are needed to better understand the feedback between the smoke plume and the jet stream.

\section{Acknowledgments}

We would like to thank the European Space Agency (ESA) for providing the GOME level 1 data as 
part of the ESA GOME calibration/validation program.

\section{Reference}

Currie, L.A., J.E. Dibb, G.A. Klouda, B.A. Benner, J. M. Conny, S. R. Biegalski, D.B. Klinedinst, D.R. Cahoon, and N.C. Hsu, The pursuit of isotopic and molecular fire tracers in the polar atmosphere and cryosphere, Radiocarbon, 40, 381-390, 1998.

Dibb, J. E., et al., Biomass burning signatures in the atmosphere and snow at Summit, Greenland: An event on 5 August 1994, Atmospheric Environment, 30, 553-561, 1996.

Herman, J.R., P.K. Bhartia, O. Torres, N.C. Hsu, C.J. Seftor, E. Celarier, Global distribution of absorbing aerosols from Nimbus-7/TOMS data, J. Geophys. Res., 102, 16911-16921, 1997.

Hsu, N. C., J. R. Herman, P. K. Bhartia, C. J. Seftor, O. Torres, A. M. Thompson, J. F. Gleason, T. F. Eck, and B. N. Holben, Detection of biomass burning smoke from TOMS measurements, Geophys. Res. Lett., 23, 745-748, 1996.

Hsu, N. C., J. R. Herman, O. Torres, B. N. Holben, D. Tanre, T. F. Eck, A. Smirnov, B. Chatenet, and F. Lavenu, Comparisons of the TOMS aerosol index with sun-photometer aerosol optical thickness: results and applications, accepted by J. Geophys. Res., 1998.

Jaross, G., A. Krueger, R. P. Cebula, C. Seftor, U. Hartmann, R. Haring, and D. Burchfield, Calibration and postlaunch performance of the Meteor 3/TOMS instrument, J. Geophys. Res., 100, 2985-2995, 1995.

Key, J., R. Stone, J. Maslanik, and E. Ellefsen, The detectability of sea-ice leads in satellite data as a function of atmospheric conditions and measurement scale, Ann. Glaciol., 17, ?, 1993.

Lindsay, R. and D. Rothrock, The calculation of surface temperature and albedo of Arctic sea ice 
from AVHRR, Ann. Glaciol., 17, 391-397, 1993.

Stocks, B. J., The extent and impact of forest fires in northern circumpolar countries, Global Biomass Burning: Atmospheric, Climatic and Biospheric Implication, The MIT Press, Cambridge, Massachusetts, 1991.

Torres, O., P. K. Bhartia, J. R. Herman, Z. Ahmad, and J. Gleason, Derivation of aerosol properties from satellite measurements of backscattered ultraviolet radiation. Theoretical basis, $J$. Geophys. Res., 103, 17099-17110, 1998.

Seftor, C. J., N. C. Hsu, J. R. Herman, P. K. Bhartia, O. Torres, W. Rose, D. Schneider, and N. Krotkov, Detection of volcanic ash clouds from Nimbus-7/TOMS, J. Geophys. Res., 102, $16749-16760,1997$. 


\section{Figure Captions}

Figure 1. Six successive daily maps of TOMS aerosol index measurements from 3 August, 1998 to 8 August, 1998, superimposed with the NCEP $500 \mathrm{mb}$ geopotential height and wind. This NCEP layer altitude was chosen because the direction of the smoke plumes during this time period corresponds to the eastward and then northward trajectory paths passing over Canada in an approximately $500-\mathrm{mb}$ layer. A box is drawn over Greenland to highlight the region of interest.

Figure 2. Maps of TOMS reflectivity measured at $380 \mathrm{~nm}$ over Greenland from 3 August, 1998 to 8 August, 1998. The borders of these reflectivity maps are consistent with the boxes drawn over Greenland in Figure 1.

Figure 3. Comparisons of the spectral dependence of the reflectivity with heavy smoke (dotted line), measured by GOME over Greenland on 6 August, 1998, with an aerosol-free spectrum (solid line) over a snow/ice surface in Greenland on 2 August, 1998. The ratio of these two spectra are depicted by the thick dashed line. The small gap and the curvature in the spectrum around $405 \mathrm{~nm}$ is an instrumental artifact from the GOME spectrometer.

Figure 4. Radiative transfer calculations of the effects of various types of tropospheric aerosols on the reflectance over dark and highly reflective surfaces. The 3 curves represent aerosols models S1 (dashed: sulfate), C1 (dotted: weakly absorbing), and C2 (solid: moderately absorbing). 
Figure 5. The interannual variability of the area covered by heavy smoke (TOMS aerosol index> 2) observed over Greenland (top) and Canada (bottom) by TOMS from 1979 to 1998.

Figure 6. Monthly mean $500 \mathrm{mb}$ height field (meters) for August 1994 (top) and August 1982 (bottom). Superimposed are the mean positions of the $250 \mathrm{mb}$ polar and Arctic jet stream axes. 

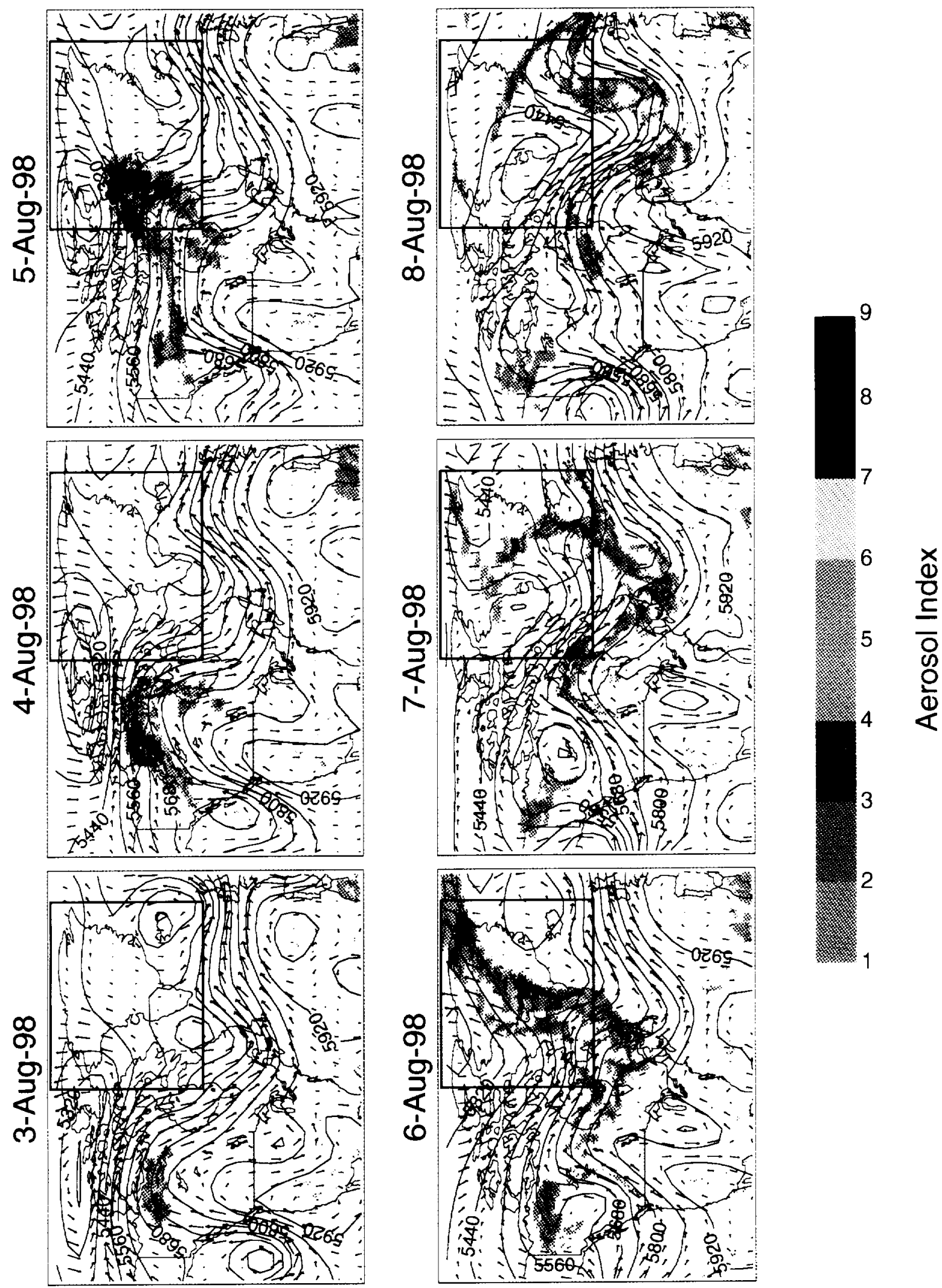

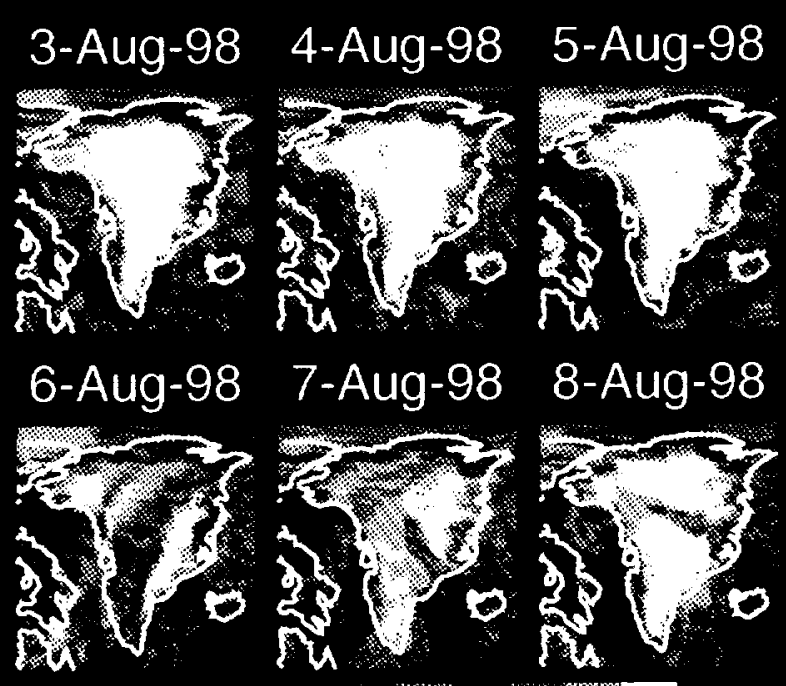

$$
\text { O } \vec{O} \text { O }
$$

Percent 


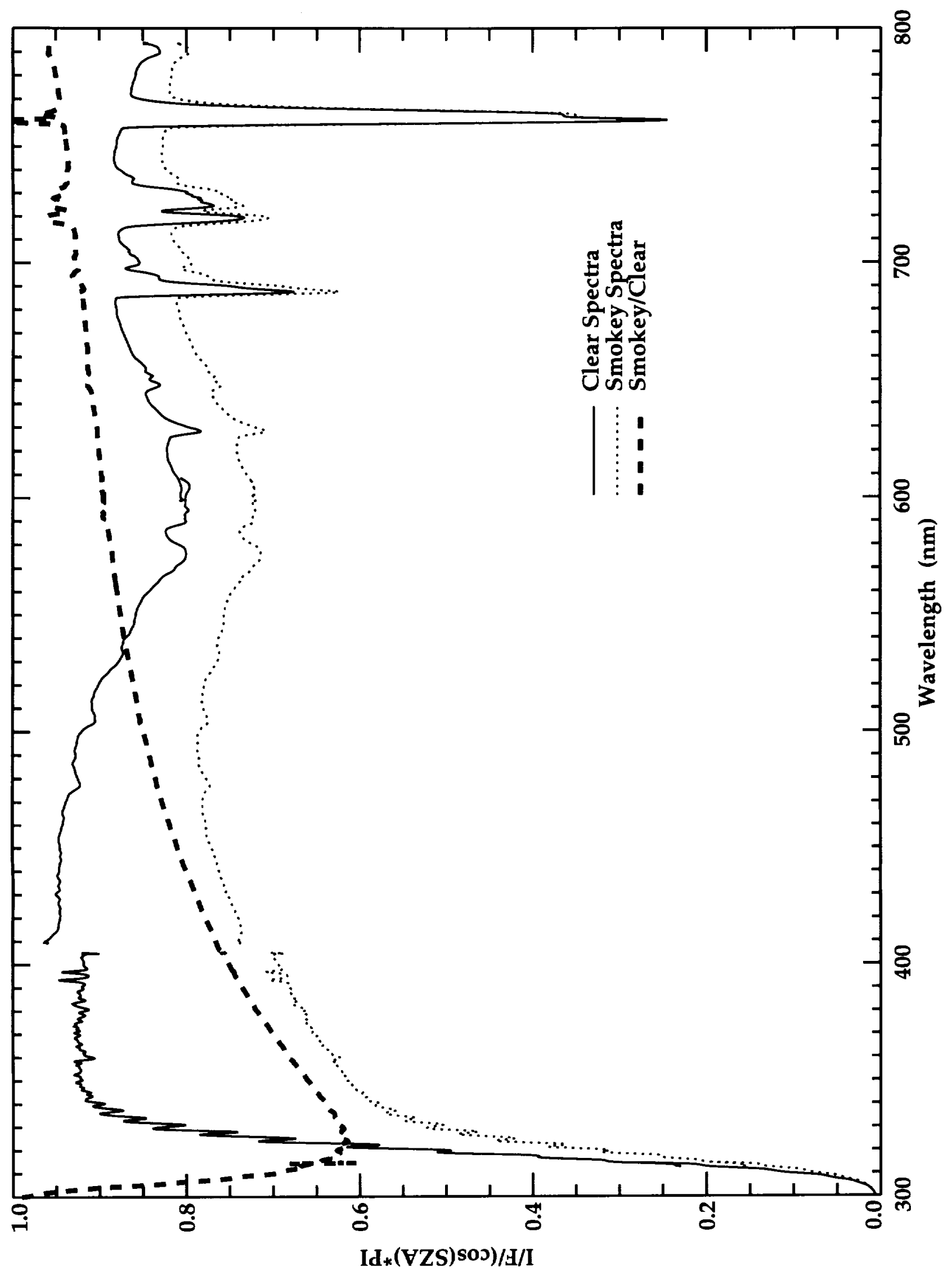

Fig 


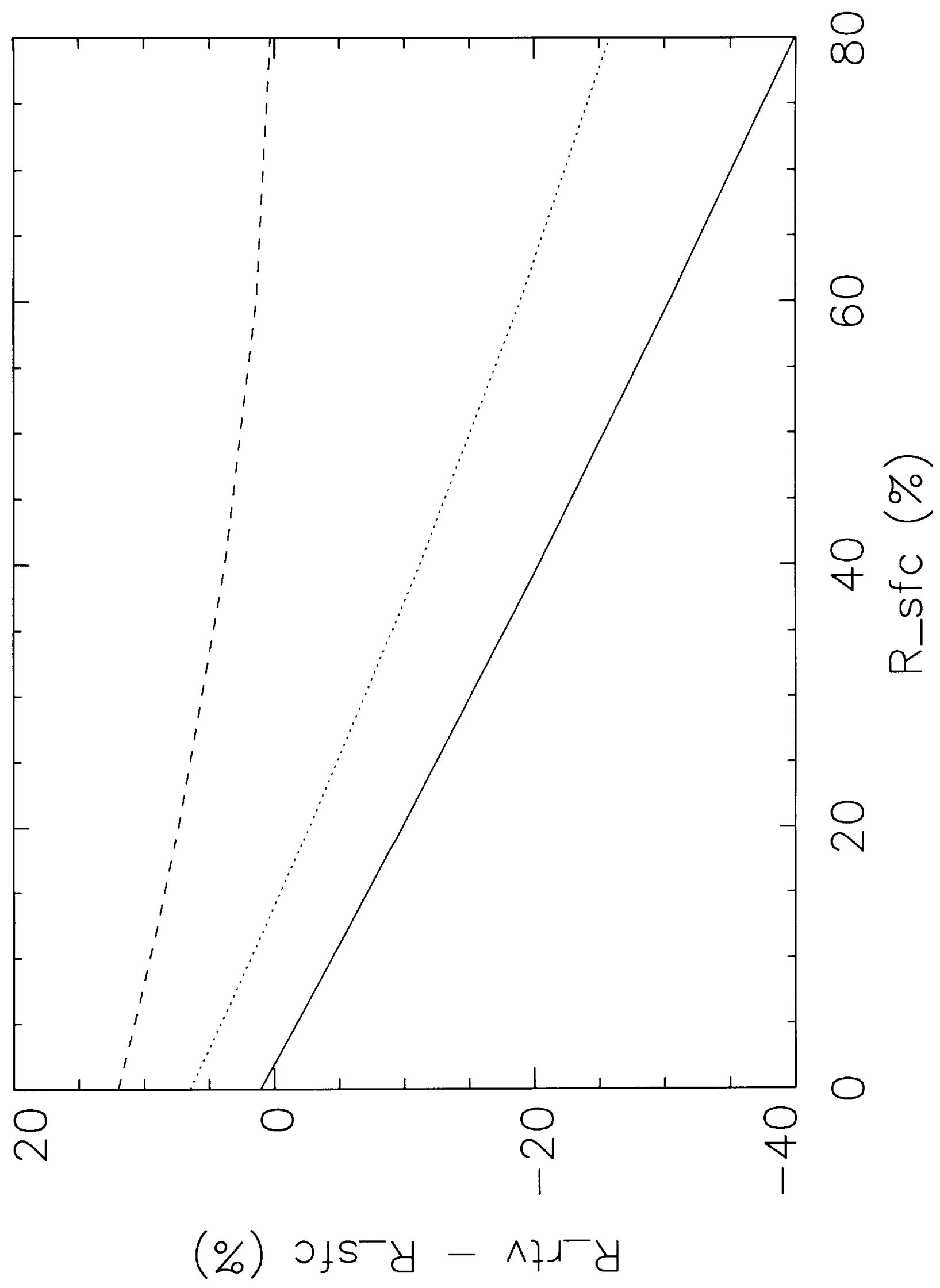

Fig. 4 


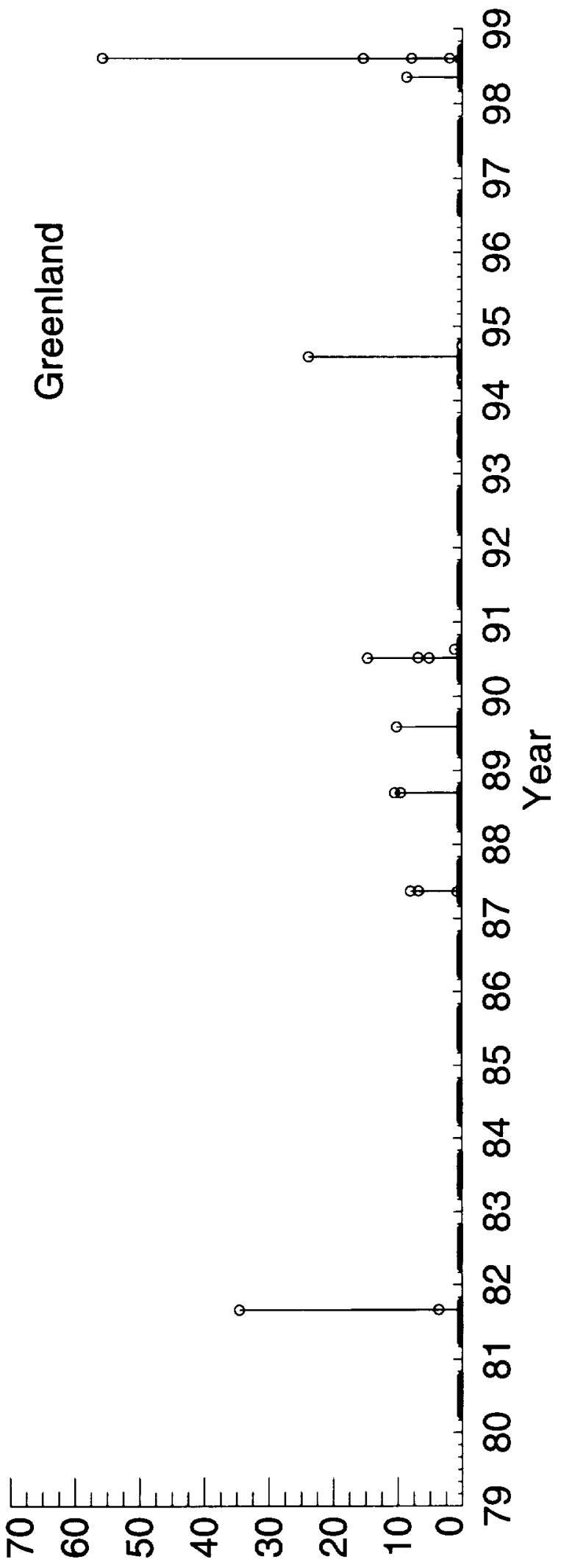

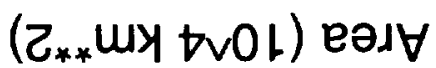

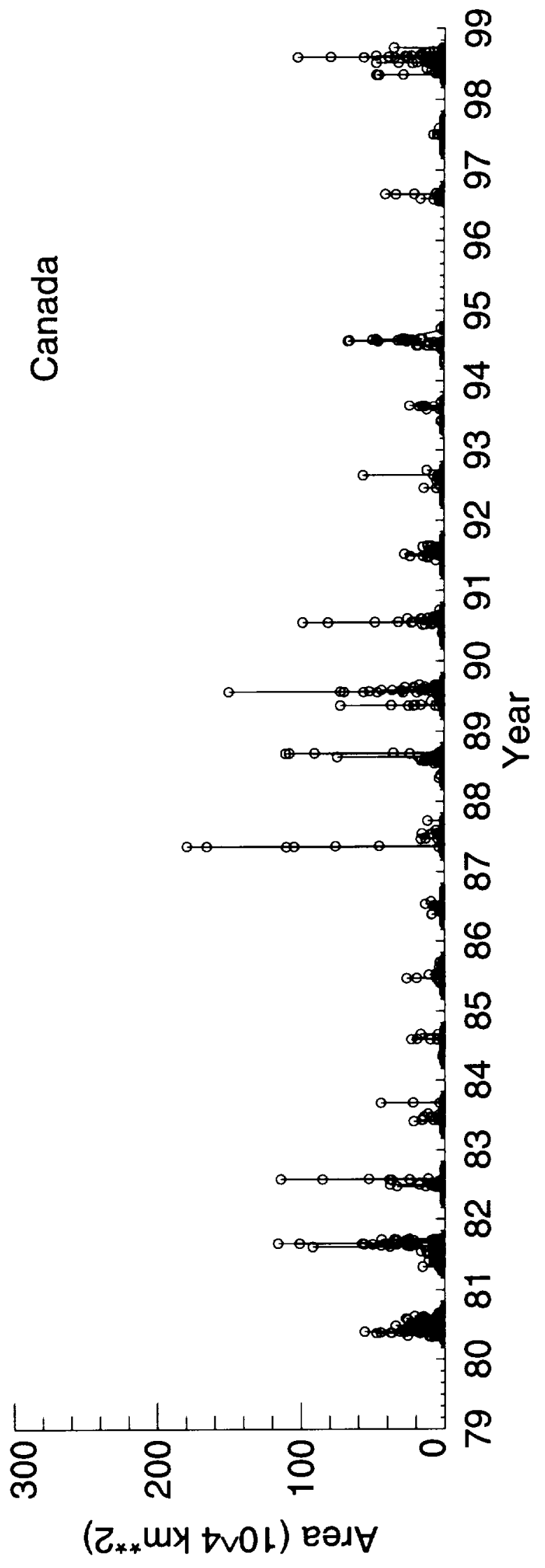

Fig. 5 

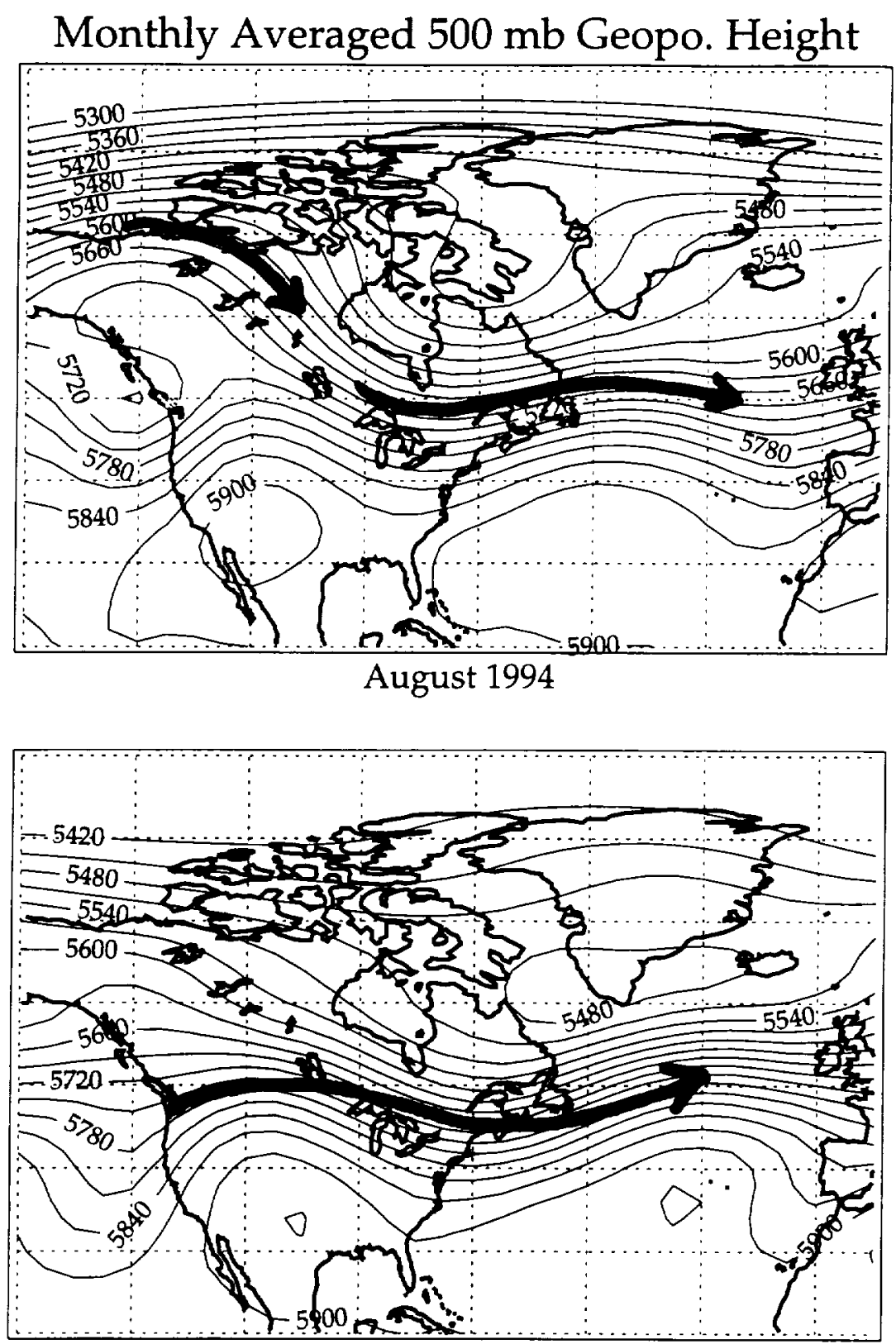

August 1982 